\title{
Electrocardiographic findings in a patient with pure septal infarction
}

\author{
Akira Tamura, Hajime Kataoka, Yoshiaki Mikuriya
}

Abstract

The electrocardiogram in a 65 year old man in whom pure septal infarction had been produced by occlusion of the septal branch during percutaneous transluminal coronary angioplasty showed that this had led to the disappearance of septal $Q$ waves and reciprocal ST segment depression in the inferior leads.

There are two published reports of pure septal infarction but neither gives detailed electrocardiographic data. ${ }^{12}$ We report on the electrocardiographic changes produced by pure septal infarction in a patient whose large septal branch was accidentally occluded during percutaneous transluminal coronary angioplasty.

Second Department of Internal Medicine, Medical College of Oita, Oita, Japan

A Tamura

H Kataoka

Y Mikuriya

Correspondence to

Dr Akira Tamura, The

Second Department of

Internal Medicine, Medical

College of Oita, 1-1506 Idai-

ga-oka, Hazama-machi, Oitagun, Oita 879-56, Japan.

Figure 1 Coronary angiograms ( $A$ and $B$ ) of the left coronary artery

before percutaneous

transluminal coronary angioplasty, showing the first septal branch (arrow on $B$ ) originating from the left anterior descending coronary artery. Coronary angiograms of the left coronary artery after angioplasty (C and D) showing successful dilatation of the stenotic lesions in the left anterior descending coronary artery and diagonal branch and accidental occlusion of the first septal branch. A and $C$, right anterior oblique view, $B$ and $D$, left superior oblique view.

\section{Case report}

A 65 year old man was admitted to our hospital with exercise induced angina. On admission, physical examination, chest radiograph, and electrocardiograms (both at rest and after a Master two-step test) were normal. An echocardiogram showed normal wall motion in the interventricular septum and slightly reduced motion in the left ventricular anterolateral wall.
Coronary angiography showed no significant narrowing of the left circumflex or right coronary arteries. The left anterior descending coronary artery (fig 1A and 1B) gave off well developed first septal and diagonal branches at the same level. The left anterior descending artery was completely obstructed just distal to the origins of the first septal and diagonal branches. Collateral vessels from the right coronary artery filled the peripheral left anterior descending artery distal to the occluded site. There were also stenoses (diameter of the lumen reduced by $90 \%$ ) of both the left anterior descending artery just proximal to the origins of the first septal branch and the proximal portion of the diagonal branch.

On the basis of these findings, percutaneous transluminal coronary angioplasty was performed on the stenoses of the left anterior descending artery and the diagonal branch. Because the two target sites were close to each other we expected that one inflation of the balloon would dilate both lesions. Slight chest pain persisted after deflation of the balloon. Repeat angiography (fig 1C and 1D) showed sufficient dilatation of the target lesions, but complete obstruction of the proximal portion of the septal branch. The electrocardiogram recorded immediately after percutaneous transluminal coronary angioplasty showed 
Figure 2

Electrocardiograms before (A) and after angioplasty (B).

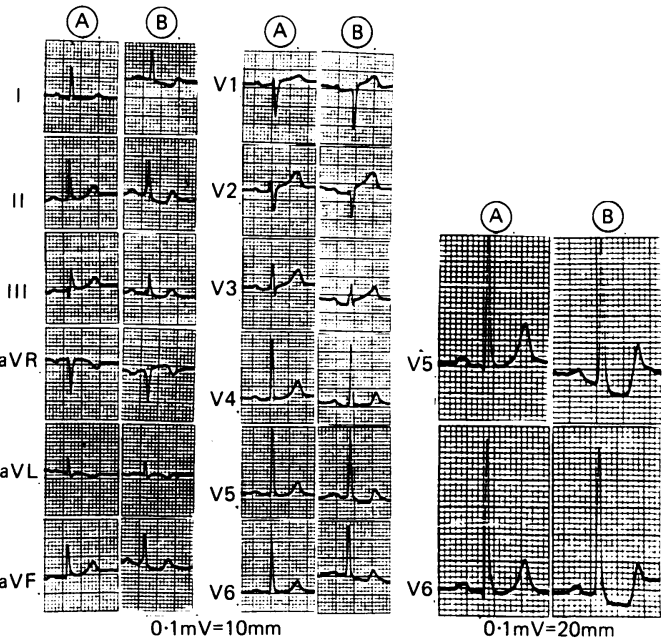

that septal $Q$ waves recorded in leads $I, V 5$, and V6 immediately before percutaneous transluminal coronary angioplasty had disappeared (fig 2). There was also slight ST segment elevation and absence or reduction of initial $R$ waves in leads V1-V3, with ST segment depression in leads I, II, III, aVF, V5, and V6. Chest pain disappeared after two hours and the maximum serum concentration of creatine kinase was 937 IU/1. Echocardiography after percutaneous transluminal coronary angioplasty showed akinesis of the anterior interventricular septum. Thallium201 myocardial imaging after percutaneous transluminal coronary angioplasty showed a perfusion defect in the anterior interventricular septum.

\section{Discussion}

Disappearance of initial $\mathrm{R}$ waves in leads $\mathrm{V} 1$ and $\mathrm{V} 2$ have been reported in patients with infarction of the septum and left ventricular anterior wall. ${ }^{34}$ On the basis of the excitation process of the isolated human heart reported by Durrer et al,,$^{5}$ this electrocardiographic finding is explained by the loss of the earliest excitation in the middle half of the left side of the interventricular septum because of septal infarction. In previous reports, however, the effects of the infarcted area in the neighbouring myocardium outside the septum could not be ruled out. We found that pure septal in- farction induced the loss of initial $\mathrm{R}$ waves in the medial precordial leads and the loss of septal $\mathrm{Q}$ waves in the lateral precordial leads. Yamaki et al reported that electrical excitation of the right ventricle contributed to the formation of septal $Q$ waves. ${ }^{6}$ But in our patient we found that septal $Q$ waves were not preserved despite a normal right ventricle. Further study will be required to clarify the contribution of the right ventricle to the genesis of septal Q waves.

In pure septal infarction we also found ST segment depression in the lateral and inferior leads, as well as ST segment elevation in leads V1-V3. Echocardiography and thallium-201 imaging showed no evidence of ischaemia in the lateral and inferior myocardium after infarction. This suggests that the ST segment depression in the lateral and inferior leads may be merely an electrical phenomenon-so called "reciprocal change". Evidence from our patient suggests that reciprocal change opposite to the ST segment elevation in the medial precordial leads caused by septal involvement may be one mechanism for the ST segment depression seen in the inferior leads during acute myocardial infarction of the left ventricular anterior wall. ${ }^{7-9}$

1 Nishimura RA, Tajik AJ, Seward JB. Distinctive twodimensional echocardiographic appearance of septal infarct secondary to isolated occlusion of first septal perforator artery. Echocardiography 1984;1:97-101.

2 Thijis Plokker HW, Ernst Sjef MPG, Van Tellingen C, Bruschke AVG. Isolated obstruction of large septal perforators. Am J Cardiol 1988;62:142-3.

3 Kossmann CE, De La Chapelle CE. The precordial electrogram in myocardial infarction. 1. Observation on cases with infarction principally of the anterior wall of the left ventricle and adjacent septum. Am Heart $J$ 1938;15: 700-20.

4 Myers GB, Klein HA, Stofer BE. Correlation of electrocardiographic and pathologic findings in anteroseptal infarction. Am Heart J 1948;36:535-75.

5 Durrer D, Van Dam TH, Feud E, James MJ, Meijler FL Arzbaecher RC. Total excitation of the isolated human heart. Circulation 1970;41:899-912.

6 Yamaki M, Ikeda K, Honma K, et al. Diagnosis of right ventricular involvement in chronic inferior myocardial infarction by means of body surface QRS changes. Cirinfarction by means of bod

7 Haraphongse $M$, Tanomsup S, Jugdutt BI. Inferior ST segment depression during acute anterior myocardial infarction: clinical and angiographic correlations. $J \mathrm{Am}$ Coll Cardiol 1984;4:467-76.

8 Lew A, Hod FH, Cercek B, Shah PK, Ganz W. Inferior ST segment changes during acute anterior myocardial infarction: a marker of the presence or absence of concomitant inferior wall ischemia. J Am Coll Cardiol 1987;10:519-26.

9 Camara EJN, Chandra N, Ouyang P, Gottlieb SH, Shapiro EP. Reciprocal ST change in acute myocardial infarction: assessment by electrocardiography and echocardiography. 